\title{
The Exploration into the Theoretical Problems of the Infiltration of Moral Education in the University PE Classes
}

\author{
Gaosheng Li \\ Public Basic Course Department \\ Wuhan Technology and Business University \\ Wuhan, P.R.China
}

\begin{abstract}
Enhancing morality and fostering talents has been the overall goal for all subjects. The thesis is to explore the existing problems with the penetrative moral education in university PE classes and to discuss the theoretical problems of the integration of $P E$ and moral education. Through the digging of moral elements in university physical education, the thesis is to find more effective educational theory and methods to facilitate the healthy body and mind development of college students. Meanwhile, it provides the referential materials for the theoretical research into moral education infiltration in university PE lessons and the teaching practice of PE.
\end{abstract}

Keyword-university PE; moral education infiltration; rational; thinking

\section{INTRODUCTION}

Strengthening morality education in PE is to stick to the morality in PE teaching and make use of the physical thoughts, spirits and culture to lead, touch and encourage students in order to facilitate the healthy development of students' body and mind; fostering talents in PE is to stick to the guiding ideas of "putting people and their health first and promoting the full-scale development" and use the scientific and effective PE teaching contents, forms, methods to change and develop people. How to find the approaches and ways of moral education and carry out the project of enhancing morality and fostering talents in all subjects has been an important task for PE teaching reform and development of universities. Nowadays, in all subjects, especially in university PE teaching, there is some shortage in physical education thought, physical education awareness, sports personality, physical specification for college students, which, in some way, influences the full development of college students in their body and mind.

\section{THE PROBLEM OF “THE BASIC TASK OF PE" WITH THE MORAL EDUCATION INFILTRATION INTO UNIVERSITY PHYSICAL EDUCATION}

The physical education in the universities of 21 st century has experienced the full-scale reform and under the guiding

The article is sponsored by the 2016 educational \& scientific plan program of Hubei province: The Study on the Filtration of Moral Education in University PE Teaching (2016GB166). thoughts of "Health First and Full Development", the basic task and goal of the new curriculum of PE and Health have been adjusted and redefined. This is a progress for the development ideas of university PE. For a long time, PE teachers in some universities have some controversial ideas about the moral education in university PE. The main problem is that they have some different ideas on the description of one of the basic tasks in the past university PE teaching and the physical functions. On the other hand, for a long time, for the university PE has been greatly influenced by the one-sided competitive trend of sports and the students' lack of attention to the PE lessons, there exists the phenomenon of deficiency in moral education of university PE teaching. The causes are as follows: firstly, the direct and indirect influence of the unhealthy ways and customs of lack of social morality and ethics; secondly, some misunderstandings of people on the moral education of university PE classes; thirdly, the lack of theoretical guidance of moral education infiltration into college students' physical education; fourthly, the lack of teachers' self-cultivation and moral education functions.

\section{THE PROBLEM OF "PhySiCAL NATURE OF SPORTS" WITH THE MORAL EDUCATION INFILTRATION INTO UNIVERSITY PHYSICAL EDUCATION}

In different historical periods, philosophers, educators, thinkers and gymnasts have profoundly demonstrated the relationship of PE teaching and moral education. They all realized the importance of PE on the moral development of people and they think that students' moral quality of thought can be fostered in PE teaching. The foreign researchers in physical education generally regard the development of honesty and fairness as the main quality of all athletes of different ages and levels in participating into different activities, because the physical matches must obey the rules and have no shortcuts. Athletes must win the respect depending on the sportsmanship and sports ability.

For a long time, there is some controversy on whether the university PE teaching is to strengthen students' physique or cultivate the personality, but from the perspective of PE's shaping the whole development of people's body and mind, the university PE not only has the function of strengthening 
students' physique, but it also has the function of cultivating the personality of students. In terms of physical nature of sports, the university PE has only one nature, which is to strengthen college students' physique. Therefore, the infiltration of moral education in university PE should be the goal and task of university PE lessons.

\section{THE PROBLEM OF "THE TEACHING GOAL OF SPORTSMANSHIP" WITH THE MORAL EDUCATION INFILTRATION INTO UNIVERSITY PHYSICAL EDUCATION}

The basic goal of moral education in university PE teaching can be summarized into five aspects: competition and enterprising education, the education of obeying the rules, unity and cooperation, responsibility and duties, and personality. First is the teaching goal of competition and enterprising. In the learning and exercising activities of college students, the fostering of students' moral qualities can be regarded as the teaching goal of university PE teaching, in which college students can learn the method of physical competition and understand the meaning of physical competition. Second is the teaching goal of obeying the rules. In the learning and exercising activities of college students, college students must learn to strictly obey the physical rules and form the habit of obeying the physical rules. They can fairly take part into the physical activities and obey the physical ethics. College PE teaching activities can help students learn the law and rules and promote the growth of colleges. Third is the teaching goal of unity and cooperation. In the learning and exercising activities of college students, college PE teachers should lead and organize students to take part in different kinds of collective activities and other activities involving the cooperation. In this way, college students can foster their good qualities like helping each other and cooperation. Fourth is the teaching goal of responsibilities and duties. In the learning and exercising activities of college students, college PE teachers should foster college students' responsibilities and attitudes towards their learning, work and life through letting students finish PE learning tasks. Fifth is the teaching goal of the personality of putting people first. In the learning and exercising activities of college students, college PE teachers should realize that what PE serves is people and the purpose of PE is to promote the whole development of people's body and mind.

\section{THE PROBLEM OF “THE TEACHING PRINCIPLE OF PHYSICAL ETHICS" WITH THE MORAL EDUCATION INFILTRATION INTO UNIVERSITY PHYSICAL EDUCATION}

\section{A. Abiding by the Principle of Sports Culture Inheritance}

The PE classes should make full use of the traditional culture of Chinese nationalities, the cultural connotations of Chinese and foreign sports and the educational function of the qualities special in physical activities to carry out the direct or indirect moral infiltration; at the same time, the PE teachers should correctly deal with the dialectical relationship between physical education and moral education. Otherwise, the main function of PE teaching will be greatly discounted and the practical effect of strengthening the body will be deeply influenced.

\section{B. Abiding by the Principle of Sports Spirit Incentive}

The PE classes should make use of some sports spirits like the spirit of being faster, higher and stronger or friendship first and game second to encourage students to strengthen their body and enhance their physique and to further increase their impetus into their study.

\section{Abiding by the Principle of Sports Thinking Education}

The PE classes should set up the theme of sports thinking education and organize the PE teaching activities purposely. Before the activities, the PE teachers must be clear of a theme about ideological education and match all the activities with the design and arrangement of the whole class. At the same time, the PE teachers should infiltrate the ideological education into the whole process of the teaching activities so as to enhance the college students' cultivation of ideological morality by means of the special approaches and methods in PE lessons.

\section{Abiding by the Principle of Sports Teaching Art}

It is an art to combine the physical education and moral education. It is necessary to design, prepare and arrange the teaching activities so as to prepare for the ideological education in PE lessons. PE teachers should stick closely to the teaching theme and choose the needed music, pictures, teaching tools and scenes to design the class, thus the ideological education can be carried out in the interesting and lively teaching atmosphere. Therefore, the PE teaching with the moral infiltration should be artistic, scientific, thoughtful and educational.

\section{E. Abiding by the Principle of PE Teachers being Teachers}

PE teachers should infect their students with their personality charm and guide the students with their professional dedication spirit. The PE teachers should try to be a model and set a good example for all the students in their PE teaching, to reach the purpose of imparting the knowledge and the thoughts on how to be a useful person.

\section{THE PROBLEM OF "THE TEACHING CONTENTS OF PHYSICAL ETHICS” WITH THE MORAL EDUCATION INFILTRATION INTO UNIVERSITY PHYSICAL EDUCATION}

\section{A. Sport Idea}

The ideas are also called concepts. The sport ideas are the concepts, thoughts and awareness used in the physical activities. One PE teacher's sport ideas, thoughts and awareness will influence and guide his teaching style. In university PE activities, the sport ideas are regarded as the important moral education contents. Under the influence of those sport ideas, college students should have the correct, healthy and positive attitudes toward the physical activities and can build their bodies actively and strengthen their will to do everything. The university PE activities should pay more attention to the ideological education to help college 
students set up the correct physical outlook on life, values, health, virtues. At the same time, the PE teachers should lead students to read some books written by some famous educators.

\section{B. Sports Spirit}

Spirit refers to one's primordial spirit. The sports spirit is that students should be energetic in the physical activities. The university PE activities should regard the sports spirit as the important moral education contents and inspire and encourage college students to build their body and increase their interest in doing exercises.

\section{Sports Culture}

Culture, generally speaking, refers to the total amount of the material wealth and spiritual wealth created in the process of the human history development. The specific meaning of culture is referring to common people's social habits with the various, regional, national and epochal character. The sports culture refers to the total amount of the body health and sports spirit wealth created in the PE activities. PE itself is very creative, reflected in the new records created in the sports competition and the behaviors challenging the human limits. In university PE activities, the sports culture has become the important content of moral education and thus the college students will get familiar to the long-history Olympic spiritual culture, sports culture and traditional sports culture. The more culture the college students learn, the more contributions they can make for the human social peace, progress and development and the more responsibilities and duties they can take to inherit the human $\mathrm{PE}$ civilization and build the strong body to work for the country development.

\section{Sports Will}

The will refers to the psychological process in which people set up a goal and overcome the difficulties to realize the goal. It includes self-discipline, self-control and perseverance of people. The sports will is that in the PE activities, people try to realize the setting PE goal through their self-discipline, self-control and perseverance. In the university PE activities, the sports will has become one of the moral education contents and college students' selfdiscipline, self-control and perseverance have been cultivated, thus the students will put those good qualities into their study and they will understand more about human value.

\section{E. Sports Regulations}

The regulations are some rules that must be obeyed. The sports regulations refer to the sports rules, systems and regulations obeyed in the $\mathrm{PE}$ activities. The sports regulations can be used to restrict the bad PE behaviors. In university PE activities, the sports regulations have become the contents of moral education and thus college students will understand those rules and regulations so as to regulate their PE behaviors. In this way, those students can foster their good qualities of obeying the rules and regulations and thus have the law consciousness.

\section{CONCLUSION}

In carrying out the moral education in university $\mathrm{PE}$ lessons, the PE teachers should find solutions to those above problems and then adopt some effective ways to impart the contents of moral education to students. As long as the university $P E$ classes really attach more and more importance to the cultivation of good qualities of college students, the moral education infiltration into the PE lessons can become more and more meaningful and effective.

\section{REFERENCES}

[1] Sun Hui. The Research into the Implementation of Moral Character Education in PE Teaching[M]. People's Publishing House, 2002

[2] Guo Yongfu. Putting Educating People and Moral Education First[J]. The Chinese Educational Journal, 2010 